\title{
A violência sofrida pelos profissionais de enfermagem no ambiente de trabalho
}

Violence suffered by nursing professionals in the workplace

Violencia que sufren los profesionales de enfermería en el lugar de trabajo

Letícia Oliveira Silva $^{1 *}$, Karla Talita Santos Silva ${ }^{1}$, Brunna Thais Costa ${ }^{1}$, Giuliana de Fatima Gonçalves Braga Escolástico Ribeiro1, Flabiane Carvalho Cordeiro Casimiro², Brenda Cristina Rodrigues de Almeida ${ }^{2}$, Joice Fernanda Costa Quadros ${ }^{2}$, Laudileyde Rocha Mota ${ }^{3}$, Bruno de Pinho Amaral $^{4}$, Sylmara Corrêa Monteiro ${ }^{5}$.

\section{RESUMO}

Objetivo: Conhecer a violência sofrida por profissionais de enfermagem. Métodos: Foi realizado um estudo de revisão integrativa de literatura, as bases de busca foram a Biblioteca Virtual em Saúde (BVS), Literatura Latino-Americana e do Caribe em Ciências da Saúde (LILACS) e Scientific Electronic Library Online (Scielo), foram utilizados os descritores profissionais de enfermagem, violência no trabalho e exposição a violência com auxílio do operador booleano "and". Resultados: As modalidades de violência que os profissionais de enfermagem estão expostos são inúmeras, dentre as quais incluem-se a violência verbal, física, assédio moral, psicológica, institucional, individual e também coletiva. Os principais atores dos atos violentos são os pacientes, familiares dos pacientes e colegas de trabalho. Considerações finais: A partir dos resultados evidencia-se que os profissionais de enfermagem estão expostos a variadas modalidades de violência no ambiente de trabalho, seja no cenário hospitalar ou atenção primária à saúde. É urgente a necessidade de políticas públicas que garantam proteção aos profissionais de enfermagem.

Palavras-chave: Violência, Exposição a violência, Profissionais de enfermagem.

\begin{abstract}
Objective: Knowing the violence suffered by nursing professionals. Methods: An integrative literature review study was carried out, the search bases were the Virtual Health Library (VHL), Latin American and Caribbean Literature in Health Sciences (LILACS) and Scientific Electronic Library Online (Scielo), were nursing professional descriptors, workplace violence and exposure to violence with the help of the Boolean operator "and" were used. Results: There are numerous types of violence that nursing professionals are exposed to, including verbal and physical violence, psychological, institutional, individual and collective harassment. The main actors in violent acts are patients, patients' families and co-workers. Final considerations: Based on the results, it is evident that nursing professionals are exposed to various types of violence in the workplace, whether in the hospital setting or in primary health care. There is an urgent need for public policies that guarantee protection for nursing professionals.
\end{abstract}

Keywords: Violence, Exposure to violence, Nurse practitioners.

\footnotetext{
${ }^{1}$ Faculdades Unidas do Norte de Minas Gerais (FUNORTE), Montes Claros - MG.

${ }^{*}$ E-mail: leticiaoliveirasilva.enf@gmail.com

${ }^{2}$ Faculdade de Saúde Ibituruna (FASI), Montes Claros - MG.

${ }^{3}$ Faculdade Santo Agostinho (FASA), Montes Claros - MG.

${ }^{4}$ Universidade Estadual de Montes Claros (UNIMONTES), Montes Claros - MG.

${ }^{5}$ Instituto Federal de Educação, Ciência e Tecnologia do Norte de Minas Gerais (IFNMG), Montes Claros - MG.
}

SUBMETIDO EM: 7/2021

ACEITO EM: 8/2021

PUBLICADO EM: 8/2021 


\section{RESUMEN}

Objetivo: Conocer la violencia que sufren los profesionales de enfermería. Métodos: Se realizó un estudio de revisión integradora de la literatura, las bases de búsqueda fueron la Biblioteca Virtual en Salud (BVS), Literatura Latinoamericana y del Caribe en Ciencias de la Salud (LILACS) y Biblioteca Electrónica Científica en Línea (Scielo). Descriptores profesionales de enfermería, violencia laboral y Se utilizaron exposición a la violencia con la ayuda del operador booleano "y". Resultados: Existen numerosos tipos de violencia a los que están expuestos los profesionales de enfermería, incluida la violencia verbal y física, el acoso psicológico, institucional, individual y colectivo. Los principales actores de los actos violentos son los pacientes, las familias de los pacientes y los compañeros de trabajo. Consideraciones finales: A partir de los resultados, es evidente que los profesionales de enfermería están expuestos a diversos tipos de violencia en el ámbito laboral, ya sea en el ámbito hospitalario o en la atención primaria de salud. Existe una urgente necesidad de políticas públicas que garanticen la protección de los profesionales de enfermería.

Palabras clave: Violencia, Exposición a la violencia, Enfermeras practicantes.

\section{INTRODUÇÃO}

O trabalho na área da saúde apresenta uma multiplicidade de dificuldades e necessita de uma contínua comunicação entre os profissionais de saúde e usuários do sistema de saúde, relacionamento permeado pelo planejamento e condições do ambiente de trabalho, assim como pela preparação da força de trabalho, principalmente composta pelos trabalhadores de enfermagem. Nota-se em pesquisas realizadas no Brasil que certas ocasiões vividas no ambiente de trabalho têm potencial para estimular absenteísmo, incapacidades, sofrimentos, dor, adoecimento, desgaste psíquico, sofrimento mental e físico, além de possibilidade de aposentadoria prematura para os profissionais (DAL PAl, et al., 2018; BORDIGNON M, MONTEIRO MI, 2016).

Dentre as questões que repercutem no esgotamento dos profissionais está a violência. A violência se define como um fenômeno histórico e sociocultural, sendo conceituada pela Organização Mundial da Saúde (OMS, 2014) como a utilização do poder ou da força corporal, cometida ou ameaçada contra um indivíduo, a si mesmo ou a um grupo de indivíduos, que tenha como resultado ou que possa resultar em um dano psíquico, ferimento ou um óbito, déficit de desenvolvimento ou privação.

De acordo com a OMS (2014) a violência é uma problemática de saúde pública de caráter global, permanecendo entre os principais motivos de óbito no sexo feminino e masculino, crianças e idosos que sofrem violência sexual, mental, física, entre outras. Contudo, a OMS ratifica que esses resultados podem ser evitados por intermédio de práticas preservativas e de políticas públicas, no qual a maior parte dos atos violentos são atribuídas a causas comportamentais, econômicas, sociais, culturais e políticas que podem ser remoldadas.

Salienta-se ainda que o profissional que vivencia a violência pode apresentar redução de desempenho e nível de satisfação na esfera do trabalho, tal como acréscimo da ansiedade frente às ocorrências equivalentes, o que prejudica desfavoravelmente a sua saúde psicológica e física, principalmente no decorrer dos dois primeiros anos após o acontecimento violento (JOHANSEN IH, et al., 2017).

A violência no trabalho pode ocasionar sobrecarga, afastamentos e exaustão profissional, além de prejudicar na proteção do paciente, elevando os índices de falhas, acarretando nesse trabalhador a sensação de insegurança e assim gerando o sentimento de impotência, desgaste emocional e físico, caracterizando exposição a riscos psicossociológicos (FLÓRIDO HG, et al., 2020; INTERNATIONAL LABOUR ORGANIZATION, 2018).

Em relação à violência contra os profissionais de enfermagem, um estudo executado pelo Conselho Federal de Enfermagem e a Fiocruz englobando todo o território brasileiro, expôs que 19,8\% dos 
trabalhadores de enfermagem já sofreram alguma modalidade de violência na esfera do trabalho. E dentre esses profissionais, $66 \%$ revelaram que sofreram violência psicológica. A investigação revelou ainda que $71 \%$ dos profissionais que participaram da pesquisa não se sentiam amparados na esfera do trabalho (COREN, 2015).

A violência no ambiente de trabalho é uma realidade vivenciada pelos profissionais de enfermagem, sendo, inúmeras as consequências trazidas por essa experiência, destacando-se a produção de sofrimento e riscos à saúde mental do trabalhador (SILVA-JUNIOR RF, et al., 2021).

Evidencia-se a elevação importante das reflexões acerca da violência no trabalho no cenário internacional. No entanto, exige-se o investimento em notificações, além de pesquisas que tenham como foco a temática no país, considerando-se as peculiaridades do momento atual (DAL PAI D, et al., 2018). Nessa discussão, a violência no trabalho assume um papel de destaque como um significativo problema de saúde coletiva na atualidade e, ainda que, notificada de forma tímida, ganha atenção perante os resultados negativos para a saúde dos profissionais e assistência as pacientes (BENIFICIO LSF e BARROS JPP, 2017). Assim, esse estudo buscou conhecer a violência sofrida por profissionais de enfermagem no ambiente de trabalho.

\section{MÉTODOS}

Trata-se de um estudo de revisão integrativa de literatura. Para a realização do estudo foram seguidos passos inter relacionados, a saber: caracterização acerca da temática e escolha da hipótese do estudo ou da questão de pesquisa; consideração dos critérios de elegibilidade e exclusão de pesquisas/amostragem ou seleção nas bases, definição dos dados a serem retirados das pesquisas incluídas/categorização das investigações; análise das pesquisas selecionadas, interpretações dos desfechos e apresentação da revisão (MENDES KDS, et al., 2018).

A questão da pesquisa levantada foi: Como ocorre a experiência da violência no trabalho contra os profissionais de enfermagem? A busca de artigos para o presente estudo foi realizada durante os meses de maio e junho de 2021. As bases de dados secundários utilizadas foram a Literatura Latino-Americana e do Caribe em Ciências da Saúde (LILACS), Scientific Electronic Library Online (Scielo) e Biblioteca Virtual em Saúde (BVS) do Ministério da Saúde.

Para coleta de dados utilizou-se um instrumento validado de extração de dados para revisões integrativas de literatura com as seguintes categorias de análise: identificação da publicação (título principal, autores, periódico de publicação e ano de publicação, delineamento da pesquisa, centro de realização da pesquisa, objetivo principal do estudo, área temática, classificação qualis do periódico de publicação do estudo, nível de evidência do estudo primário, principais resultados, dentre outros. A seleção foi realizada de forma individual pelos autores com auxílio do instrumento citado para comparação dos resultados.

Considerou-se como descritores os termos selecionados por meio dos Descritores em Ciências da Saúde, desse modo, os descritores foram: exposição a violência, violência no trabalho e profissionais de enfermagem. Foi utilizado o operador booleano "and" para seleção mais assertiva. Na busca inicial foram identificadas 171 publicações potencialmente elegíveis para a amostragem final, sendo 78 artigos na base de dados Biblioteca Virtual em Saúde, 36 na Scielo e 57 na LILACS.

Para composição da amostra final, foram considerados como critérios de inclusão: disponibilidade de artigos completos, redação do texto em português, inglês ou espanhol e produções publicadas entre os anos de 2016 e 2021. Os artigos selecionados foram analisados na íntegra, primariamente, foi realizada análise dos títulos e resumos, sendo em seguida realizada a leitura completa do artigo.

Os critérios de exclusão elencados foram: dissertações, teses, cartilhas, sites de internet de órgãos não governamentais, textos incompletos, estudos de revisão de literatura e estudos que não faziam uma análise efetiva acerca do objeto de estudo. Nesse sentido, após considerar-se os critérios de inclusão e exclusão foram identificados para a amostra final 18 artigos (Figura 1). 
Figura 1 - Fluxograma de busca dos artigos.

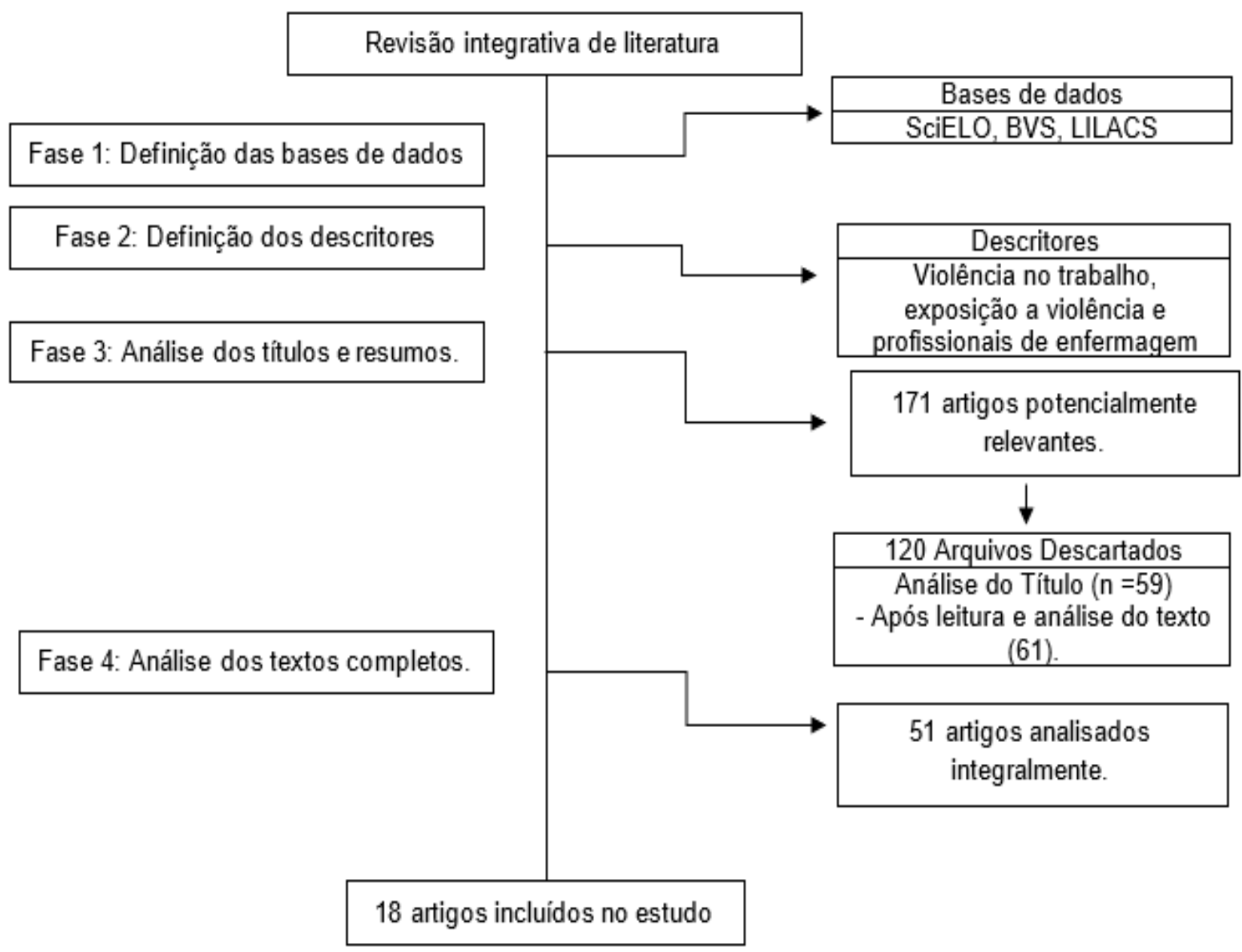

Fonte: Silva LO, et al., 2021.

\section{RESULTADOS}

No Quadro 1 apresenta-se a síntese das principais informações dos artigos selecionados para investigação organizados de acordo com o ano de publicação e autores, título do manuscrito, título da revista de publicação, método do estudo, objetivo principal e desfechos mais relevantes do estudo. 
Quadro 1 - Artigos que compõem a amostra final de análise.

\begin{tabular}{|c|c|c|c|c|c|}
\hline Ano/Autor(es) & Título & Periódico & Delineamento & Objetivo & Desfechos \\
\hline $\begin{array}{c}\text { Celestino CL, et al. } \\
(2020) .\end{array}$ & $\begin{array}{l}\text { Riscos psicossociais } \\
\text { relacionados ao trabalho do } \\
\text { enfermeiro da Saúde da } \\
\text { Família e estratégias de } \\
\text { gerenciamento. }\end{array}$ & Rev Esc Enferm USP. & $\begin{array}{l}\text { Estudo exploratório de } \\
\text { abordagem qualitativa } \\
\text { dos dados. }\end{array}$ & $\begin{array}{l}\text { Analisar os riscos psicossociais } \\
\text { relacionados ao trabalho do enfermeiro } \\
\text { da Saúde da Família e as estratégias de } \\
\text { gerenciamento para minimizá-los. }\end{array}$ & $\begin{array}{l}\text { Foram identificados riscos psicossociais } \\
\text { relacionados ao contexto de trabalho e } \\
\text { presença de violência psicológica. }\end{array}$ \\
\hline Vieira GLC. (2017). & $\begin{array}{l}\text { Agressão física contra } \\
\text { técnicos de enfermagem em } \\
\text { hospitais psiquiátricos. }\end{array}$ & $\begin{array}{c}\text { Rev Bras Saúde } \\
\text { Ocup. }\end{array}$ & Estudo transversal. & $\begin{array}{l}\text { Caracterizar os casos de agressão física } \\
\text { contra técnicos de enfermagem em dois } \\
\text { hospitais psiquiátricos e analisar os } \\
\text { fatores relacionados à ocorrência } \\
\text { desses eventos. }\end{array}$ & $\begin{array}{l}\text { A agressão física é vivenciada com alta } \\
\text { frequência entre os técnicos de } \\
\text { enfermagem, que relatam pouco suporte } \\
\text { institucional e sentimentos de } \\
\text { insegurança no ambiente de trabalho. }\end{array}$ \\
\hline $\begin{array}{l}\text { Leite CN, et al. } \\
\qquad(2020) .\end{array}$ & $\begin{array}{l}\text { Violência na Estratégia de } \\
\text { Saúde da Família: riscos } \\
\text { para a saúde dos } \\
\text { trabalhadores e ao } \\
\text { atendimento }\end{array}$ & Rev enferm UERJ. & $\begin{array}{l}\text { Estudo qualitativo, } \\
\text { descritivo. }\end{array}$ & $\begin{array}{l}\text { Identificar a ocorrência da violência na } \\
\text { Estratégia de Saúde da Família e } \\
\text { analisar as repercussões para a saúde } \\
\text { dos trabalhadores e ao atendimento. }\end{array}$ & $\begin{array}{l}\text { A violência ocupacional é um risco a } \\
\text { integridade física e psíquica dos } \\
\text { trabalhadores e a qualidade do } \\
\text { atendimento. }\end{array}$ \\
\hline $\begin{array}{c}\text { Sturbelle SCl, et al. } \\
\text { (2019). }\end{array}$ & $\begin{array}{l}\text { Violência no trabalho em } \\
\text { saúde da família: estudo de } \\
\text { métodos mistos }\end{array}$ & Acta Paul Enferm. & $\begin{array}{l}\text { Estudo misto, do tipo } \\
\text { concomitante. }\end{array}$ & $\begin{array}{l}\text { Verificar a prevalência de violência no } \\
\text { trabalho em Unidades de Saúde da } \\
\text { Família, caracterizar as vítimas e } \\
\text { conhecer as implicações dascondições } \\
\text { e da organização do trabalho na } \\
\text { exposição dos trabalhadores. }\end{array}$ & $\begin{array}{l}\text { A violência se mostrou prevalente no } \\
\text { trabalho em unidades de saúde da } \\
\text { família. }\end{array}$ \\
\hline $\begin{array}{c}\text { Trindade LL, et al. } \\
\text { (2019). }\end{array}$ & $\begin{array}{l}\text { Agressão verbal no trabalho } \\
\text { da enfermagem na área } \\
\text { hospitalar }\end{array}$ & Rev. Eletr.Enferm & Estudo de método misto. & $\begin{array}{l}\text { Revelar a banalização da agressão } \\
\text { verbal contra a enfermagem no cenário } \\
\text { e indícios da banalização do fenômeno. }\end{array}$ & $\begin{array}{l}\text { A elevada incidência de agressão verbal } \\
\text { contra a enfermagem no cenário e } \\
\text { indícios da banalização do fenômeno. }\end{array}$ \\
\hline $\begin{array}{c}\text { Santos MS, et al. } \\
(2017) .\end{array}$ & $\begin{array}{l}\text { O enfrentamento à violência } \\
\text { no âmbito da estratégia } \\
\text { saúde da família: desafios } \\
\text { para a atenção em saúde. }\end{array}$ & $\begin{array}{l}\text { Rev Bras Promoç } \\
\text { Saúde, Fortaleza. }\end{array}$ & $\begin{array}{l}\text { Estudo descritivo com } \\
\text { abordagem qualitativa. }\end{array}$ & $\begin{array}{l}\text { Compreender os desafios enfrentados } \\
\text { pelos profissionais da Estratégia Saúde } \\
\text { da Família (ESF) no desenvolvimento da } \\
\text { assistência à saúde em áreas } \\
\text { vulneráveis à violência. }\end{array}$ & $\begin{array}{l}\text { O desempenho da assistência em áreas } \\
\text { vulneráveis à violência representa a } \\
\text { exposição dos profissionais a situações } \\
\text { adversas. }\end{array}$ \\
\hline
\end{tabular}




\begin{tabular}{|c|c|c|c|c|c|}
\hline Ano/Autor(es) & Título & Periódico & Delineamento & Objetivo & Desfechos \\
\hline $\begin{array}{l}\text { Hagopian EM, et al. } \\
\text { (2017). }\end{array}$ & $\begin{array}{l}\text { Assédio moral no trabalho } \\
\text { em enfermagem. }\end{array}$ & Rev baiana enferm. & Pesquisa qualitativa. & $\begin{array}{l}\text { Compreender as vivências dos } \\
\text { enfermeiros resultantes da exposição ao } \\
\text { assédio moral no ambiente detrabalho. }\end{array}$ & $\begin{array}{l}\text { Ao entender a vivência dos profissionais } \\
\text { diante das consequências do assédio } \\
\text { moral, pôde-se mostrar que eles } \\
\text { submetem-se a situações degradantes. }\end{array}$ \\
\hline $\begin{array}{c}\text { Santos TA, et al. } \\
(2020) .\end{array}$ & $\begin{array}{l}\text { Associação entre variáveis } \\
\text { relacionadas à precarização } \\
\text { e afastamento do trabalho no } \\
\text { campo da enfermagem. }\end{array}$ & $\begin{array}{l}\text { Ciência \& Saúde } \\
\text { Coletiva. }\end{array}$ & Estudo transversal. & $\begin{array}{l}\text { O objetivo é verificar associações entre } \\
\text { variáveis relacionadas à precarização e } \\
\text { o afastamento do trabalho por motivo de } \\
\text { saúde no campo da enfermagem. }\end{array}$ & $\begin{array}{l}\text { Há precarização no campo da } \\
\text { enfermagem e o Estado favorece o } \\
\text { adoecimento das trabalhadoras ao } \\
\text { manter estas condições de trabalho. }\end{array}$ \\
\hline $\begin{array}{c}\text { Ogenler O Yapıci G. } \\
\text { (2018). }\end{array}$ & $\begin{array}{l}\text { Avaliação da violência física } \\
\text { contra assistentes de } \\
\text { pesquisa e enfermeiros em } \\
\text { um hospital universitário. }\end{array}$ & Acta Bioethica. & Estudo transversal. & $\begin{array}{l}\text { Determinar a prevalência de violência } \\
\text { física e fatores relacionados entre } \\
\text { assistentes e enfermeiros. }\end{array}$ & $\begin{array}{l}\text { Um de cada dez trabalhadores na área } \\
\text { de saúde demonstra ser vítima de } \\
\text { violência física no local de trabalho. }\end{array}$ \\
\hline $\begin{array}{l}\text { Machado MH, et al. } \\
\text { (2015). }\end{array}$ & $\begin{array}{l}\text { Condições de trabalho da } \\
\text { enfermagem. }\end{array}$ & Enferm. Foco. & Estudo transversal. & $\begin{array}{l}\text { Analisar a situação das condições de } \\
\text { trabalho em que a equipe de } \\
\text { enfermagem atua, incluindo variáveis } \\
\text { em relação às condições laborais e de } \\
\text { relacionamento. }\end{array}$ & $\begin{array}{l}\text { Enfermeiros realizam suas atividades } \\
\text { com grande pressão psicológica e } \\
\text { desgaste físico, decorrente de } \\
\text { condições de trabalho precárias, má } \\
\text { organização da gestão do sistema. }\end{array}$ \\
\hline $\begin{array}{l}\text { Fernandes APFC e } \\
\text { Passos JP (2018). }\end{array}$ & $\begin{array}{l}\text { Delineamento da violência } \\
\text { sofrida pela equipe de } \\
\text { enfermagem na emergência } \\
\text { hospitalar. }\end{array}$ & $\begin{array}{l}\text { Rev enferm UERJ, } \\
\text { Rio de Janeiro. }\end{array}$ & $\begin{array}{l}\text { Estudo qualitativo, } \\
\text { descritivo. }\end{array}$ & $\begin{array}{l}\text { Caracterizar, na visão do profissional de } \\
\text { enfermagem, a violência sofrida a partir } \\
\text { da sua relação com o usuário ou } \\
\text { acompanhante visita do sistema público } \\
\text { de saúde em um serviço de emergência } \\
\text { hospitalar. }\end{array}$ & $\begin{array}{l}\text { Foram encontrados problemas } \\
\text { relacionados à gestão hospitalar como } \\
\text { fator desencadeador da violência, tendo } \\
\text { o manejo do profissional de enfermagem } \\
\text { para esta situação o seu principal } \\
\text { atenuante/agravante. }\end{array}$ \\
\hline $\begin{array}{l}\text { Cordenuzzia OCP, et } \\
\text { al. (2017). }\end{array}$ & $\begin{array}{l}\text { Estratégias utilizadas pela } \\
\text { enfermagem em situações } \\
\text { de violência no trabalho em } \\
\text { hemodiálise. }\end{array}$ & Rev Gaúcha Enferm. & $\begin{array}{l}\text { Pesquisa de abordagem } \\
\text { qualitativa, do tipo } \\
\text { descritiva e exploratória. }\end{array}$ & $\begin{array}{l}\text { Identificar as estratégias utilizadas pelos } \\
\text { trabalhadores de enfermagem de um } \\
\text { serviço de hemodiálise em situações de } \\
\text { violência perpetrada por pacientes } \\
\text { durante a assistência. }\end{array}$ & $\begin{array}{l}\text { As estratégias utilizadas são descritas } \\
\text { nas categorias: Tolerar a violência pela } \\
\text { condição de saúde do paciente; } \\
\text { Contornar as situações de conflito e } \\
\text { ceder à solicitação do paciente; Adotar } \\
\text { um posicionamento de rejeição à } \\
\text { violência; e Se afastar do paciente } \\
\text { agressor. }\end{array}$ \\
\hline
\end{tabular}




\begin{tabular}{|c|c|c|c|c|c|}
\hline Ano/Autor(es) & Título & Periódico & Delineamento & Objetivo & Desfechos \\
\hline $\begin{array}{l}\text { Flórido HG, et al. } \\
\qquad(2020) .\end{array}$ & $\begin{array}{l}\text { Gerenciamento das } \\
\text { situações de violência no } \\
\text { trabalho na Estratégia de } \\
\text { Saúde da Família pelo } \\
\text { enfermeiro. }\end{array}$ & $\begin{array}{l}\text { Texto \& Contexto } \\
\text { Enfermagem. }\end{array}$ & $\begin{array}{l}\text { Estudo qualitativo, } \\
\text { descritivo e exploratório. }\end{array}$ & $\begin{array}{l}\text { Identificar as situações de violência no } \\
\text { cotidiano de trabalho dos profissionais } \\
\text { de saúde da Estratégia de Saúde da } \\
\text { Família e descrever as condutas } \\
\text { adotadas por esses profissionais } \\
\text { perante as situações de violência } \\
\text { identificadas. }\end{array}$ & $\begin{array}{l}\text { Foram identificadas situações de } \\
\text { violência interpessoal e violência } \\
\text { coletiva, exemplificadas pelo contato } \\
\text { com violência armada no território, } \\
\text { discriminação racial, violência de pares } \\
\text { e violência sofrida pelo usuário, como a } \\
\text { violência doméstica, afetando } \\
\text { diretamente o profissional. }\end{array}$ \\
\hline $\begin{array}{l}\text { Silva RM, et al. } \\
\text { (2020). }\end{array}$ & $\begin{array}{l}\text { Precarização do mercado de } \\
\text { trabalho de auxiliares e } \\
\text { técnicos de Enfermagem no } \\
\text { Ceará, Brasil. }\end{array}$ & $\begin{array}{l}\text { Ciência \& Saúde } \\
\text { Coletiva. }\end{array}$ & $\begin{array}{l}\text { A pesquisa utilizou } \\
\text { abordagem exploratória. }\end{array}$ & $\begin{array}{l}\text { Analisar o mercado de trabalho de } \\
\text { auxiliares e técnicos de enfermagem no } \\
\text { Ceará, nos anos de } 2013 \text { a } 2017 \text {, nos } \\
\text { aspectos relacionados à precarização } \\
\text { do trabalho. }\end{array}$ & $\begin{array}{l}25,5 \% \text { dos entrevistados afirmaram ter } \\
\text { sofrido algum tipo de violência no } \\
\text { trabalho. }\end{array}$ \\
\hline $\begin{array}{l}\text { Souza JSR, et al. } \\
(2020) .\end{array}$ & $\begin{array}{c}\text { Relações interpessoais entre } \\
\text { enfermeiro-paciente na } \\
\text { perspectiva da violência } \\
\text { atual. }\end{array}$ & Rev Fun Care Online. & $\begin{array}{l}\text { Estudo descritivo- } \\
\text { reflexivo. }\end{array}$ & $\begin{array}{l}\text { Refletir sobre a importância da relação } \\
\text { interpessoal entre enfermeiro-paciente } \\
\text { na perspectiva da violência atual. }\end{array}$ & $\begin{array}{l}\text { As relações interpessoais podem evitar } \\
\text { que atos de violência sejam praticados } \\
\text { no ambiente de trabalho. }\end{array}$ \\
\hline $\begin{array}{l}\text { Scozzafave CMS, et } \\
\text { al. (2019). }\end{array}$ & $\begin{array}{l}\text { Riscos psicossociais } \\
\text { relacionados ao enfermeiro } \\
\text { no hospital psiquiátrico e } \\
\text { estratégias de } \\
\text { gerenciamento. }\end{array}$ & Rev Bras Enferm. & Pesquisa qualitativa. & $\begin{array}{l}\text { Caracterizar a presença de riscos } \\
\text { psicossociais relacionados ao trabalho } \\
\text { do enfermeiro em um hospital } \\
\text { psiquiátrico e as estratégias de } \\
\text { gerenciamento desses riscos. }\end{array}$ & $\begin{array}{l}\text { Os resultados mostraram problemas } \\
\text { psicossociais relacionados ao trabalho } \\
\text { dos enfermeiros psiquiátricos. }\end{array}$ \\
\hline Sé SC, et al. (2020). & $\begin{array}{c}\text { Violência física, abuso verbal } \\
\text { e assédio sexual sofridos por } \\
\text { enfermeiros do atendimento } \\
\text { pré-hospitalar }\end{array}$ & Enferm. Foco. & Estudo descritivo. & $\begin{array}{l}\text { Identificar os tipos de violência sofridos } \\
\text { pelos enfermeiros do APH móvel. }\end{array}$ & $\begin{array}{l}\text { A violência no Atendimento Pré } \\
\text { Hospitalar é real e latente. }\end{array}$ \\
\hline $\begin{array}{c}\text { Oliveira CS, et al. } \\
\text { (2020). }\end{array}$ & $\begin{array}{l}\text { Violência no trabalho em } \\
\text { unidades de pronto } \\
\text { atendimento: vivências de } \\
\text { enfermeiros* }\end{array}$ & $\begin{array}{l}\text { Rev. Latino-Am. } \\
\text { Enfermagem. }\end{array}$ & Estudo qualitativo. & $\begin{array}{l}\text { Compreender a percepção de } \\
\text { enfermeiros de unidades de pronto } \\
\text { atendimento sobre a violência } \\
\text { vivenciada no trabalho. }\end{array}$ & $\begin{array}{l}\text { Os enfermeiros sofrem atos de violência } \\
\text { por pessoas externas e internas, das } \\
\text { próprias unidades de pronto } \\
\text { atendimento. }\end{array}$ \\
\hline
\end{tabular}

Fonte: Silva LO, et al., 2021 


\section{DISCUSSÃO}

Em relação ao ambiente de trabalho, os profissionais de enfermagem experienciam momentos intensamente sensíveis, os quais incluem, a violência infligida pelos pacientes, membros da família e até mesmo por colegas de trabalho. São exemplos de modalidades de violência infligidas a esses profissionais, a corporal, verbal, mental, sexual, moral e institucional pela utilização deliberada de poder, com o objetivo de acarretar danos ao desenvolvimento moral, psicológico, físico, social ou espiritual (VIEIRA GLC, et al., 2017; LIMA MP, et al., 2018).

É apropriado ressaltar que as próprias características laborais comuns aos profissionais de enfermagem, os tornam vulneráveis a situações de violência no trabalho, pois, dado que esses profissionais exercem suas atribuições em equipes compostas por vários profissionais, com organização inflexível e sob rotineira pressão, dessa forma, sofrem frequentemente conflitos resultantes das relações interpessoais com colegas, pacientes, membros familiares e outros colegas que formam as equipes de saúde (HAGOPIAN EM, et al., 2017).

Nesse contexto, compreende-se que durante a experiência da hospitalização, o paciente pode vivenciar sentimentos negativos. Ao se ver diante do fracasso das expectativas em relação ao processo de hospitalização e doença, esse indivíduo pode apresentar comportamentos violentos impulsos. Por conseguinte, o adoecimento pode ser produtoras de tensões, sobretudo, no cenário hospitalar (INTERNATIONAL LABOUR ORGANIZATIONAL, 2018).

Assim, nessa discussão, insere-se a violência no ambiente de trabalho ou a violência no trabalho. Essa modalidade de violência pode ser conceituada como qualquer ato de caráter voluntário de uma pessoa ou mesmo grupo de pessoas contra um grupo ou indivíduo, que seja cometido no ambiente de trabalho propriamente dito ou ao redor desse ambiente, tendo como resultado alguma possibilidade de dano físico ou mental associado à segurança e saúde do trabalhador. Nesses atos, incluem-se quaisquer modalidades de privação, não observância de direitos previdenciários e trabalhistas ou qualquer ação negligente acerca das condições trabalhistas ou por fim a omissão de cuidados (HABIGZANG LF, 2018; INTERNATIONAL LABOUR ORGANIZATIONAL, 2018).

É importante ressaltar que identificar e analisar as modalidades de violência influencia positivamente para o planejamento e desenvolvimento de estratégias de prevenção e de assistência às vítimas (HABIGZANG LF, 2018). Em estudo realizado em um serviço hospitalar na região Sul do país com profissionais atuantes em um serviço de hemodiálise de grande porte que avaliou as condutas realizadas por profissionais de enfermagem frente a eventos violentos evidenciou-se, por exemplo, as tentativas de evitar a comunicação da violência por parte dos pacientes, e consequentemente, do sentimento de sofrimento que esse episódio violento traz ao profissional, em caráter protetivo ou preventivo (CORDENUZZI OCP, et al., 2017).

Assim, esses profissionais usaram de forma mais intensa ações individuais que significaram de certa forma aceitação e tolerância quanto às agressões sofridas. Foram relatadas também articulações de caráter coletivo e estratégias de não aceitação da violência que, na percepção dos profissionais de enfermagem, aumentaram, embora, não foram resolutivas frente aos atos de violência sofridos no trabalho (CORDENUZZI OCP, et al., 2017).

É importante salientar que a violência é frequente na sociedade, por exemplo, no cenário da Atenção Primária à Saúde em estudo realizado no Rio de Janeiro quanto às situações de violência foram registradas a violência de caráter interpessoal e também a violência coletiva, denotadas pelas ocorrências rotineiras, tais como o contato com a violência armada na área de abrangência, discriminação quanto a raça, violência entre os pares e vivência com a violência sofrida pelo usuário, como a violência na esfera doméstica (FLÓRIDO HG, et al., 2020).

Essa violência no trabalho influencia de forma direta a saúde do trabalhador e a assistência prestada pelo profissional de saúde, sobretudo, para os profissionais que compõem a equipe de enfermagem, pois, em muitos casos, essas situações agem como barreiras para a circulação do profissional no território, além de poder incorrer em agressões por parte da comunidade (DAL PAI D, et al., 2018).

Em outro inquérito que investigou as modalidades de violência sofrida por profissionais de enfermagem que trabalhavam na assistência pré-hospitalar na região sudeste do país, constatou-se a violência verbal 
como a mais frequente, acerca dos infratores, identificaram-se os familiares dos pacientes, público em geral e os próprios pacientes (SÉ ACS, et al., 2017). Resultados equivalentes foram encontrados em pesquisas realizadas na Itália, Argentina, Jordânia, Irã, Chile e Gâmbia (RODRíGUEZ CVA e PARAVIC KTM, 2020; SISAWO EJ, et al., 2017),

Considerando ainda esse cenário, na Atenção Primária à Saúde os profissionais assumem um papel significativo junto à população, sobretudo, em relação à educação em saúde, vacinação, vigilância epidemiológica e outras ações e atribuições direcionadas à prevenção de agravos à saúde. Nesse sentido, surge a discussão acerca do fluxo de atendimento das famílias acompanhadas pelas equipes e daqueles que procuram o serviço com necessidades que nem sempre estão no escopo de resolutividade desse serviço. $O$ estresse do usuário resultado da ausência de resolução em relação a demanda que ele apresenta contribui para os eventos de violência psicológica infligida contra os profissionais (LEITE CN, et al., 2020).

É fundamental considerar que, de forma geral, há uma lacuna entre a motivação de procura pelos serviços de saúde e as necessidades que possivelmente precisam ser sanadas pelos profissionais. Ou seja, a relação entre os desejos dos profissionais e dos pacientes nem sempre se constroem por interseções, gerando conflitos, em muitos casos, de resolução ruidosa. A falta de uma escuta de negociação somada à cultura da violência muito presente na sociedade pode denotar terreno fértil para a explosão da violência no trabalho e suas repercussões para os profissionais e a assistência prestada (DAL PAI D, et al., 2018).

Ainda é frequente que os pacientes da Estratégia de Saúde da Família, quando a terapêutica não responde positivamente ou por não entenderem as regras do modelo de assistência do serviço, apresentam comportamento desrespeitosos com os profissionais, acarretando, dessa forma, insatisfação (SORATTO J, et al., 2017). A postura dos pacientes no anseio por cuidados de saúde rápidos e resolutivos ou ainda, 0 anseio dos profissionais devido à violência nas áreas de abrangência, traz frequentemente insatisfação e sofrimento, uma vez que o trabalho nessa modalidade de assistência exige a construção de relações congruentes para que os cuidados sejam mais resolutivos (SORATTO J, et al., 2017).

Em relação aos principais agentes perpetuadores da violência contra os profissionais, nota-se que 0 paciente é o maior perpetrador da violência, infringindo frequentemente a violência verbal, seguida da física (DAL PAI D, et al., 2018; NOWROUZI-KIA B, 2017; FISEKOVIC KMB, 2017). Os cenários de assistência dos profissionais também são variáveis associados às situações de violência contra os profissionais (FLÓRIDO HG, et al., 2020).

A violência no trabalho também é realizada pelos próprios colegas, ou seja, profissionais de saúde que exercem cargos equivalentes ou hierarquicamente superiores, e relaciona-se ainda a precarização e a crise na saúde. Hábitos agressivos passam a ser compreendidos como expressões de descontentamento e indiferença frente ao momento precário vivenciado, que pode ser interpretado como um ato negligente as condições fundamentais de dignidade do profissional como participantes do sistema de saúde perante a sociedade (DAL PAI D, et al., 2018).

No entanto, constata-se que ainda é tímida a cultura institucional nas equipes em realizar o processo de notificação da violência vivida, situação que impossibilita a adoção de ações para o enfrentamento satisfatório dos casos de violência no trabalho. Em muitos casos, os profissionais apresentam pouco interesse em realizar a notificação dos casos de violência devido a desconhecerem seus resultados e por considerarem suas repercussões pouco impactantes na realidade do trabalho (SILVA IV, et al., 2017; FONTES KB, et al., 2016).

Há certo sentimento de naturalização bem como a banalização da violência psicológica no trabalho. Caso, não se depare com um episódio considerado grave ou aconteçam ameaças periódicas, ações formais de notificação são pouco conhecidas e utilizadas pelos profissionais. Acredita-se que uma política de desvalorização do trabalhador da saúde conjuntamente com uma sociedade em que não ocorra a punição adequada para os atos violentos incorrem na desmotivação para a denúncia e procura por resolução (LEITE CN, et al., 2020).

Acerca do trabalhador da área da saúde, a violência no trabalho impacta de forma direta a sua qualidade de vida, dado que esses trabalhadores exercem suas atividades diretamente com indivíduos que possuem 
problemas graves e complexos, sendo impossibilitados de realizar suas atribuições em razão da violência na área de trabalho e o impedimento de realizar de denúncias sobre a violência sofrida (FLÓRIDO HG, et al., 2020).

Essa violência pode influenciar negativamente também na vida destes profissionais, acarretando medo, desconforto e temor no local de trabalho, o que pode resultar em insatisfação em relação a esse ambiente somado a alterações psíquicas por intermédio de síndromes, crises alérgicas e alterações na saúde de forma global (LIMA MP, et al., 2018). As inúmeras ocorrências de violência atingem os profissionais resultando em prejuízos no trabalho, conjuntamente a transtornos de ordem física e também psicológica, envolvidos em sentimentos de ansiedade, vulnerabilidade e apatia (FLÓRIDO HG, et al., 2020).

A maneira como o profissional de enfermagem responde a essa violência no trabalho pode impactar de forma negativa ou positiva, podendo intensificar ou diminuir uma situação de violência. A resposta do profissional de enfermagem de forma imprópria, por meio de termos rudes, usando de ameaças, ironias e sarcasmo são encaradas como formas de defesa frente a violência infligida contra eles (FERNANDES APFC e PASSOS JP, 2018). A proximidade com familiares e amigos e a estruturação das redes de afeto são indicadas como formas de enfrentamento satisfatórias para a preservação da saúde mental dos profissionais frente a violência vivenciada (CARVALHO LA, et al., 2016).

As práticas terapêuticas, sobretudo, a escuta terapêutica, evidencia-se como uma estratégia efetiva para a prevenção e acolhimento em situações de vulnerabilidade e episódios de violência, assim como, facilita satisfatoriamente a autonomia, sentimentos de empatia e maior entendimento nas relações de caráter interpessoal existentes entre o profissional de enfermagem e o paciente acerca dos aspectos internos ou mesmo externos resultantes da violência (CARAVALHO LA, et al., 2016). Nesse cenário de enfrentamento, apresentam-se ainda as ferramentas educacionais em saúde, estas devem ser estratégias utilizadas no trabalho da enfermagem, pois, permitem ao profissional e ao paciente dos serviços de saúde, maximizar as áreas de atuação e permitir maior eficácia nas ocorrências de violência vividas (CARVALHO LA, et al., 2016).

Frente a essa realidade, urge a exigência de compreender e identificar as situações de risco a que os profissionais de saúde estão expostos, nas diversas regiões do país, a fim de implementar políticas públicas que sejam resolutivas as diferentes localidades (CELESTINO LC, et al., 2020). Em virtude a subnotificação da violência, tornam-se essenciais pesquisas na área para possibilitar a preservação da saúde do trabalhador submetido a atos violentos, além de colaborar para a formação de políticas públicas que se ocupem da temática, de maneira a garantir a proteção no trabalho dos profissionais de enfermagem (FERNANDES APFC e PASSOS JP, 2018).

Desse modo, nas instituições de saúde, os profissionais de enfermagem são os mais atingidos pela violência, o que exige o desenvolvimento de estratégias de enfrentamento nos ambientes de trabalho, tendo auxílio dos governos e dos conselhos classistas, com o objetivo de conscientizar acerca da relevância de se realizar as denúncias e implementar políticas de prevenção e educação para que esses profissionais possam melhor relacionar-se com os membros das equipes e também com os pacientes atendidos (TRINDADE LL, et al., 2019).

Reconhece-se como lacuna a serem analisados os resultados da violência contra os profissionais de enfermagem na qualidade do cuidado prestado aos pacientes, o que inclui o controle dos indicadores de segurança do paciente. Escutar os atores envolvidos nos episódios de violência também pode facilitar 0 melhor entendimento do fenômeno (TRINDADE LL, et al., 2019).

\section{CONSIDERAÇÕES FINAIS}

A partir dos resultados evidencia-se que os profissionais de enfermagem estão expostos a variadas modalidades de violência no ambiente de trabalho, seja no cenário hospitalar ou atenção primária à saúde. Essa violência sofrida impacta de maneira negativa sobre saúde mental e física, a satisfação e saúde do trabalhador de forma global. Salienta-se a necessidade de criação de estratégias de enfrentamento a violência no trabalho, envolvendo a conscientização dos próprios profissionais, pacientes, membros familiares, gestores e sociedade. A partir dos achados da presente investigação, reflete-se acerca da importância de políticas públicas direcionadas à segurança dos profissionais de enfermagem. 


\section{REFERÊNCIAS}

1. BENIFICIO LSF, BARROS JPP. Strategy family health and urban violence: social approaches and practices in question. SANARE Sobral, 2017; 16(1): 102-12.

2. BORDIGNON M, MONTEIRO MI. Violência no trabalho da enfermagem: um olhar às consequências. Rev Bras Enferm, 2016; 69(5): 996-9.

3. CARVALHO LA, et al. Riscos psicossociais no trabalho dos docentes de enfermagem e estratégias de coping. Rev. enferm. UFPE, 2016; 10(5): 4356-63.

4. CELESTINO LC, et al. Work-related psychosocial risks of the Family Health nurse and management strategies. Rev Esc Enferm USP, 2020; 54(2): 1-8.

5. CORDENUZZI OCP, et al. Estratégias utilizadas pela enfermagem em situações Estratégias utilizadas pela enfermagem em situações de violência no trabalho em hemodiálise Agressão verbal no trabalho da Enfermagem na área hospitalar. Rev Gaúcha Enferm, 2017; 38(2): 1-8.

6. COREN Conselho Regional de Enfermagem de São Paulo. Enfermagem em revista. Conselho Regional de Enfermagem de São Paulo. 2015.

7. DAL PAI D, et al. Physical and psychological violence in the workplace of healthcare professionals. Texto contexto-enferm, 2018; 27(1): 1-10.

8. FERNANDES APFC, PASSOS JP. Delineamento da violência sofrida pela equipe de enfermagem na emergência hospitalar. Rev enferm UERJ, 2018; 26(2): 1-5.

9. FISEKOVIC KMB, et al. Encouraging employees to report verbal violence in primary health care in Serbia: a cross-sectional study. Zdr Varst, 2017; 56(1): 11-7.

10. FONTES KB, et al. Factors associated with bullying at nurses' workplaces. Rev. Latino-Am. Enferm, 2016; 21(3): 758-64.

11. FLÓRIDO HG, et al. Gerenciamento das situações de violência no trabalho na Estratégia de Saúde da Família pelo enfermeiro. Texto \& Contexto Enfermagem, 2020; 29(20): 1-14.

12. HABIGZANG FL, et al. Violência contra Mulher: Notificações dos Profissionais da Saúde no Rio Grande do Sul. Psicologia Clínica e Cultura, 2018; 34(3): 1-9.

13. HAGOPIAN EM, et al. Assédio moral no trabalho em enfermagem. Rev baiana enferm, 2017; 31(1): 1-8.

14. INTERNATIONAL LABOUR ORGANIZATIONAL. Violence at work. World of work. Spe Issue, 2018.

15. JOHANSEN IH, et al. Changes in prevalence of workplace violence against doctors in all medical specialties in Norway between 1993 and 2014: a repeated cross-sectional survey. BMJ, 2017; 27(7): 177-97.

16. LEITE CN, et al. Violência na Estratégia de Saúde da Família: riscos para a saúde dos trabalhadores e ao atendimento. Rev enferm UERJ, 2020; 2(1)8: 1-6.

17. LIMA MP, et al. Violência sofrida pelos enfermeiros nas instituições de saúde: uma revisão da literatura. Ciências biológicas e de Saúde Unit, 2018; 4(3): 161-72.

18. MACHADO MH, et al. Condições de trabalho da enfermagem. Enferm. Foco, 2015; 6(1/4): 79-90.

19. MENDES KDS, et al. Revisão integrativa: método de pesquisa para a incorporação de evidências na saúde e na enfermagem. Texto Contexto Enferm, 2018; 17(4):758-64.

20. NOWROUZI-KIA B. The impact of workplace violence on health care workers' quality of life. Dev Med Child Neurol, 2017; 59(7): 60075.

21. OLIVEIRA CS, et al. Violence at work in emergency care units: nurses' experiences. Rev. Latino-Am. Enfermagem. 2020; 28(3): 234.

22. OGENLER O, YAPICI G. Assessment of physical violence against research assistants and nurses in an university hospital. Acta Bioethica, 2018; 24(1): 19-29.

23. ORGANIZAÇÃO MUNDIAL DA SAÚDE (OMS). Relatório mundial sobre violência e saúde. 2002. Disponível em: https://portaldeboaspraticas.iff.fiocruz.br/wp-content/uploads/2019/04/14142032-relatorio-mundial-sobre-violencia-e-saude.pdf. Acessado em: 20 de maio de 2021.

24. ORGANIZAÇÃO MUNDIAL DE SAÚDE (OMS). Relatório de status global sobre prevenção da violência: resume executivo. 2014. Disponível em: https://www.who.int/publications/i/item/WHO-NMH-NVI-14.2. Acessado em: 20 de maio de 2021.

25. PALMA A, et al. Violencia laboral en trabajadores del sector salud: revisión sistemática. Rev Med Chile, 2018; 14(6): 213-22.

26. RODRÍGUEZ CVA, et al. Verbal abuse and mobbing in pre-hospital care services. Chile. Rev. latinoam. enferm, $2017 ; 25(5): 135-42$.

27. SANTOS MS, et al. Fighting violence under the family health strategy: challenges for health care. Rev. Bras. Promoç. Saúde, 2017; 30(2): 229-38.

28. SANTOS TA, et al. Associação entre variáveis relacionadas à precarização e afastamento do trabalho no campo da enfermagem. Ciência \& Saúde Coletiva, 2020; 25(1): 123-33.

29. SÉ ASC, et al. Violência física, abuso verbal e assédio sexual sofridos por enfermeiros do atendimento pré-hospitalar. Enferm. Foco, 2020; 11(6): 135-42.

30. SILVA IV, et al. Violência no trabalho em saúde: a experiência de servidores estaduais da saúde no Estado da Bahia, Brasil. Cad. Saúde Pública, 2017; 30(10): 2112-22.

31. SILVA RM, et al. Precarização do mercado de trabalho de auxiliares e técnicos de Enfermagem no Ceará, Brasil. Ciência \& Saúde Coletiva, 2020; 25(1):135-45.

32. SISAWO EJ, et al. Workplace violence against nurses in the Gambia: mixed methods design. BMC Health Serv Res, 2017; 17(1): 311-17.

33. SILVA-JUNIOR RF, et al. Violência no trabalho contra os trabalhadores de enfermagem e seus imbricamentos com a saúde mental. Revista de Enfermagem do Centro Oeste Mineiro, 2021; 11(1): 1-9.

34. SORATTO J, et al. Insatisfação no trabalho de profissionais da saúde na estratégia saúde da família. Texto \& Contexto Enfermagem, 2017; 26(3): 1-11.

35. SCOZZAFAVE MCS, et al. Riscos psicossociais relacionados ao enfermeiro no hospital psiquiátrico e estratégias de gerenciamento. Rev Bras Enferm, 2019; 72(4): 882-9.

36. SOUZA JSR, et al. Relações interpessoais entre enfermeiro-paciente na perspectiva da violência atual. Rev Fun Care Online, 2020; 12(1): 648-53.

37. STURBELLE IC, et al. Violência no trabalho em saúde da família: estudo de métodos mistos. Acta Paul Enferm, $2019 ; 32(6): 32-41$.

38. TRINDADE LL, et al. Agressão verbal no trabalho da enfermagem na área hospitalar. Rev. Eletr. Enferm, 2019; 21(5): 33-43.

39. VIEIRA GLC, et al. Job satisfaction among nursing technicians in psychiatric hospitals in Minas Gerais Brazil. REME, 2017; 19(1): 174-9. 